\title{
Risk Factors Associated With Diabetic Retinopathy: A Cross- Sectional Study Within Palestinian Patients in Northern West Bank
}

\author{
Johnny Amer ${ }^{1 *}$, Raghad Suboh ${ }^{1}$, Manar Abualrob ${ }^{1}$, Amira Shaheen $^{2}$ \\ and Abdul Raheem Abu Shanab ${ }^{3}$ \\ ${ }^{1}$ Physiology, Pharmacology \& Toxicology Division, An-Najah National University, Nablus, Palestine, ${ }^{2}$ Division of Public Health, \\ Department of Biomedical Sciences, An-Najah National University, Nablus, Palestine, ${ }^{3}$ Department of Applied and Allied \\ Medical Sciences, Faculty of Medicine and Health Sciences, An-Najah National University, Nablus, Palestine
}

OPEN ACCESS

Edited by:

Ioanna Eleftheriadou,

National and Kapodistrian University of

Athens, Greece

Reviewed by:

Antonela Gverović Antunica,

General Hospital Dubrovnik, Croatia

Seyed Ahmad Rasoulinejad,

Babol University of

Medical Sciences, Iran

Chantal Dolan,

CMD Consulting, Inc., United States

*Correspondence:

Johnny Amer

j.amer@najah.edu

Specialty section:

This article was submitted to Diabetes Clinical Epidemiology,

a section of the journal

Frontiers in Clinical Diabetes

and Healthcare

Received: 05 July 2021 Accepted: 21 September 2021

Published: 12 October 2021

Citation:

Amer J, Suboh R, Abualrob M, Shaheen $A$ and Abu Shanab AR (2021) Risk Factors Associated With Diabetic Retinopathy:

A Cross-Sectional Study

Within Palestinian Patients in Northern West Bank.

Front. Clin. Diabetes Healthc. 2:736715. doi: 10.3389/fcdhc.2021.736715
Risk factors associated with diabetes mellitus (DM) have been widely researched worldwide, but the determinants of these factors among diabetic retinopathy (DR) in Palestine are currently unclear. We aimed to assess the prevalence of DR among DM in Northern West Bank and identify factors associated with DR natural history. Patients with Type 2 diabetes (T2D) ( $n=300$, age $>18$ years) from a main diabetic center covering all northern provinces of Palestine were enrolled to this cross-sectional research. Demographic information including age, sex, and duration of T2D was obtained. Moreover, $\mathrm{HbA1C}$, BMl, hypertension (HTN), controlled T2D, current smoking, and total cholesterol level were assessed. Potential correlations between these factors and DR diagnosed by ophthalmologist were evaluated using different tests on SPSS version 22. Prevalence of DR among our population was 30\%; $47.8 \%$ of these patients showed mild non-proliferative DR (NPDR), 23.3\% moderate NPDR, 16.7\% severe NPDR, and 12.2\% proliferative DR (PDR). Univariate logistic regression analysis showed age $(p=0.007), \mathrm{HTN}$ $(p=0.022)$, uncontrolled T2D ( $p=0.025)$, and duration of T2D $(<0.001)$ were mostly associated with DR while multivariate logistic regression showed duration of T2D as the major and solely risk factor for prevalence of DR $(p<0.0001)$ and were positively correlated with severities of NPDR and being a strong predictor in the PDR ( $p=0.001)$. We identified several important risk factors that affect DR, which could assist to develop effective strategies for metabolic disease prevention among populations in Palestine. Furthermore, our data suggest a necessity to control sugar serum levels and HTN.

Keywords: diabetic retinopathy, diabetes mellitus, northern West Bank, duration of DM, prevalence

\section{INTRODUCTION}

Diabetes mellitus (DM) is one of the most common chronic diseases worldwide, and it continues to increase in prevalence and disease burden (1). Diabetic retinopathy (DR), a common complication of DM, is the leading cause of impaired vision in adults worldwide (2). Patients with DR may suffer from damaged blood vessels of the light-sensitive tissue at the back of the eye (retina) and any form

Abbreviations: T2D, type 2 diabetes; DR, diabetic retinopathy DR; HTN, hypertension; NPDR, non-proliferative diabetic retinopathy; PDR, proliferative diabetic retinopathy. 
of diabetes, type 1 , type 2 , or gestational may lead to DR complications. Hypertension, smoking, hyperlipidemia, and some races were suggested as factors for DR progressions among DM in patients $(1,2)$.

DR is largely asymptomatic in the early stages, and there is a need for regular eye screening for patients with diabetes to enable timely diagnosis and subsequent management of the condition (3). Although in practice the early clinical features of DR complication are evident in the fundus on ophthalmoscopic examination, the initial diagnosis of diabetic retinopathy may be based on functional changes in electroretinography (ERG), retinal blood flow, and retinal blood vessel calibre (4). Thus, DR is currently categorized based on the presence of vascular (and closely associated) lesions and on the other hand through the absence or presence of neovascularization. There are two general categories: (a) non-proliferative diabetic retinopathy (NPDR) and (b) proliferative diabetic retinopathy (PDR) (2). Several studies recently have focused on the prognostic issues of DR; however, there is a significant lack of awareness of this disease in terms of risk factors and its outcomes. We thus conducted a population-based survey among Palestinian population with Type 2 diabetes (T2D). The purpose of this study the prevalence and identify potential risk factors of DR among $\mathrm{T} 2 \mathrm{D}$ patients.

\section{PATIENTS AND METHODS}

\section{Study Design and Study Population}

This study is a cross-sectional study of T2D patients $(n=300$, age above 18 years) based on current World Health Organization diagnostic criteria for diabetes (5). The study on patients with T2D recruitment was conducted from February to October 2020 from the Palestine Diabetes National Center Nablus. The center covers patients from all northern geographical provinces of the West Bank, Palestine, including Nablus, Jenin, Tulkarm, Tubas, and Salfit. The patients were randomly selected from patient data profiles as the first 150 male and the first 150 females from the files that were arranged alphabetically with a total number of 300 patients who underwent fundoscopic examination and have regular follow-up visits to the institute since 2016 until now. Patients who take Avastin and had laser therapy were excluded from the study. The ethics committee of An-Najah National University approved the study, and written informed consent was obtained from all participants during recruitment. All methods were performed in accordance with the relevant guidelines and regulations.

\section{Information Evaluated in This Study}

Detailed information was collected with regard to sex, age $(>18)$, cigarette smoking, alcohol use, and residency. In addition to blood pressure measurement, physical examinations included body height, weight, and circumferences of the waist, hip, and abdomen. Moreover, hemoglobin A1C (HbA1C) and total cholesterol levels were included.

\section{Diabetic Retinopathy Diagnosis}

Diabetic retinopathy was diagnosed by funduscopy. In cases where diabetic ophthalmic complications were suspected, then additional imaging modalities were used, including optical coherence tomography for the diagnosis of diabetic macular edema, and fluorescein angiography in cases where neovascular complications like optic disk or retinal neovascularization (i.e., proliferative diabetic retinopathy) were suspected.

\section{Definitions}

Hypertension was defined as an average systolic blood pressure (SBP) of $\geq 140 \mathrm{mmHg}$ and/or an average diastolic blood pressure (DBP) of $\geq 90 \mathrm{mmHg}$, or current use of any medication for treating hypertension within 2 weeks or any combination of the above. (6 Currently smoking patients were defined as active smokers for the last 3 years prior and during the data collection. An $\mathrm{HbAlc}$ above $7 \%$ was identified as uncontrolled T2D. A normal level of total cholesterol in blood is defined as total blood cholesterol below 5.18 $\mathrm{mmol} / \mathrm{l}$. Body mass index (BMI) was calculated as the ratio of weight to height squared $\left(\mathrm{kg} / \mathrm{m}^{2}\right)$. According to standard criteria in Palestinian adults, participants with a BMI $\geq 24$ and $<28 \mathrm{~kg} / \mathrm{m}^{2}$ were classified as overweight, and those with a BMI $\geq 28 \mathrm{~kg} / \mathrm{m}^{2}$ were classified as obese (5).

\section{Statistical Analysis}

Continuous variables are presented as means [standard deviations (SD)], and categorical variables are expressed as percentages [95\% confidence intervals (Cis)]. Categorical variables were analyzed using the chi-squared test. The risk factors of BMI, age, smoking, total cholesterol, and uncontrolled T2D were analyzed by bivariate analysis. Determinants of duration of T2D BMI, currently smoking, hypertension (HTN), total cholesterol, and uncontrolled T2D were assessed by multivariate linear regression analysis after adjustment for confounding factors that were statistically significant. Statistical significance was defined as a two-tailed $\mathrm{p}<0.05$. Statistical analyses were undertaken using the computer software SPSS (version 15.0 for Windows; SPSS, Chicago, IL, USA).

\section{RESULTS}

\section{Descriptive Characteristics of Patients}

The mean age of T2D patients was $58.82 \pm 10.3$ years, the mean duration of $\mathrm{T} 2 \mathrm{D}$ was $8.9 \pm 7.3$ years, and the mean BMI was $30.28 \pm 5.4 ; 133(34.4 \%)$ of patients were smokers, 197 patients (65.4\%) have HTN, and 130 patients (34.3\%) have high total cholesterol.

A total of 300 patients were included in this study, with equal numbers of males and females. The prevalence of DR was $30 \%$ (90 patients), distributed as 43 patients with mild NPDR (14.3\%), 21 patients with moderate NPDR (7.0\%), 15 patients with severe NPDR (5.0\%), and 11 patients with PDR (3.7\%). DR occurred in 49 males and 41 females with a 1.2:1 male to female ratio.

Our results summarized in Table 1 revealed no significant association between BMI, currently smoking patients, and 
gender with DR. On the other hand, age, duration of T2D, HTN, uncontrolled T2D, and cholesterol were found significantly associated with the occurrence of DR with p-values 0.007, $<0.001,0.021,0.020$, and 0.003 , respectively.

\section{Logistic Regression Model for Factors Predicting DR}

The factors predicting DR are summarized in Table 2. The table displays the univariate regression of $\mathrm{DR}$ with other variables indicating the association between DR and duration of T2D, older age, presence of HTN, currently smoking patients, uncontrolled T2D (which is defined as HbAlc more than 7\%), and the presence of normal level of total cholesterol in blood (defined as total blood cholesterol less than $200 \mathrm{mg} / \mathrm{dl}$ ). Moreover, the multiple regression analysis in Table 3 shows a highly significant positive association of only duration of T2D with DR $(p<0.001)$ while no association between DR and HTN, currently smoking, uncontrolled T2D, age, and total cholesterol was noticed in contrary to the findings in the univariate regression. Figure 1 shows a linear correlation of duration of $\mathrm{T} 2 \mathrm{D} /$ years with the severities of $\mathrm{DR}$ and being a strong predictor in the PDR $(\mathrm{p}=0.001)$.

\section{DISCUSSION}

This is the first study to report factors influencing DR severities among T2D patients aged $\geq 18$ years in northern Palestine. To date, there are a limited number of studies published on retinopathy in patients with T2D in Palestine. Therefore, this study aimed to assess the prevalence of DR among Palestinian T2D patients and highlight the risk factors associated for its prediction. In our current study, the risk factors associated with DR of $\mathrm{HbAlc}$ and $\mathrm{HTN}$ were associated with severe DR (6-10). Tight glycemic and blood pressure control remains the cornerstone in the primary prevention of DR (11). However, glycemic control was considered as the most important factor for preventing retinopathy in patients with diabetes (12) and intensive therapy effectively delays the onset and slows the progression of diabetic retinopathy (12). Our findings appear to corroborate the results reported in other studies indicating HTN and glycemic control appear to have a direct relationship with development of DR.

In the duration of diabetes, a significant association was noticed between longer duration of T2D and DR occurrence. Similar findings were found in several other studies $(6,7,10,13$, 14), which considered it as the predictor of DR (15). Moreover, in line with other studies $(12,13,16)$, there was no significant association indicated between gender and the occurrence of DR. In addition, our results indicated no significant association of DR with gender, unlike other studies $(12,14)$ that showed an increase in the incidence of DR in male patients. Regarding BMI, studies showed controversial data; some show no association with the development of DR $(13,17)$, while others showed increased BMI with a positive association with $\operatorname{DR}(3,18,19)$. Our findings demonstrated BMI as a non-significant indicator associated with risks of DR. Majority of studies show that smoking is not likely to be an important risk factor for DR $(12,17,20,21)$. Our results were consistent with these studies. However, a few studies demonstrate a relationship between smoking and DR (5). DR incidences were reported in elder patients (14), and age appeared as an independent risk factor for DR (22). Our findings support this evidence, as do other studies $(12,13)$.

A controversial study displayed an association between cholesterol and DR. A previous study demonstrated that reducing elevated blood lipids could have an impact to slow the progression of retinopathy (23). However, high levels of total cholesterol had been reported to be associated with lower risk of $\mathrm{DR}$, and it could be a protective factor against DR (24). In the current report, patients with DR [59 (68.6\%)] had normal serum levels of total cholesterol as compared to patients without DR [102 $(49.8 \%)]\left(\chi^{2}=8.708\right.$ and $\left.p=0.003\right)$. A study performed in Gaza Strip among male patients with T2D demonstrated a significantly higher prevalence of neuropathy, nephropathy, cardiovascular disease, and recurrent infections among patients with DR as compared to those without DR (25).

TABLE 1 | The association between risk factors and DR.

\begin{tabular}{|c|c|c|c|}
\hline & With DR $\mathrm{n}=90$ & Without DR $n=210$ & \\
\hline Min-max & & & $p=0.742$ \\
\hline Duration of $\mathrm{T} 2 \mathrm{D} \pm \mathrm{SD}$ (years) min-max & $13.3 \pm 7.2(2-35)$ & $7 \pm 6.5(0-28)$ & $\begin{array}{l}\mathrm{t}=7.540 \\
p<0.001\end{array}$ \\
\hline Currently smoking & $\begin{array}{l}\text { Yes } n=38(42.2 \%) \\
\text { No } n=52(57.8 \%)\end{array}$ & $\begin{array}{l}\text { Yes } n=95(45.2 \%) \\
\text { No } n=115(54.8 \%)\end{array}$ & $\begin{array}{l}X^{2}=0.232 \\
p=0.630\end{array}$ \\
\hline Uncontrolled T2D (HbA1C > 7\%) & $\begin{array}{c}\text { Yes } \mathrm{n}=84(93.3 \%) \\
\text { No } \mathrm{n}=6(6.7 \%)\end{array}$ & $\begin{aligned} \text { Yes } n & =174(83.3 \%) \\
\text { No } n & =35(16.7 \%)\end{aligned}$ & $\begin{array}{l}X^{2}=5.402 \\
p=0.020\end{array}$ \\
\hline Cholesterol (normal is below $5.18 \mathrm{mmol} / \mathrm{l}$ ) & $\begin{array}{c}\text { Abnormal }=27(31.4 \%) \\
\text { Normal }=59(68.6 \%)\end{array}$ & $\begin{array}{l}\text { Abnormal = } 103(50.2 \%) \\
\text { Normal }=102(49.8 \%)\end{array}$ & $\begin{array}{l}X^{2}=8.708 \\
p=0.003\end{array}$ \\
\hline Gender & $\begin{array}{l}\text { Female }=41(45.6 \%) \\
\text { Male }=49(51.9 \%)\end{array}$ & $\begin{array}{l}\text { Female }=109(51.9 \%) \\
\text { Male }=101(54.4 \%)\end{array}$ & $\begin{array}{l}X^{2}=0.773 \\
p=0.379\end{array}$ \\
\hline
\end{tabular}

${ }^{a}$ Average systolic blood pressure (SBP) of $\geq 140 \mathrm{mmHg}$ and/or an average diastolic blood pressure (DBP) of $\geq 90 \mathrm{mmHg}$ 


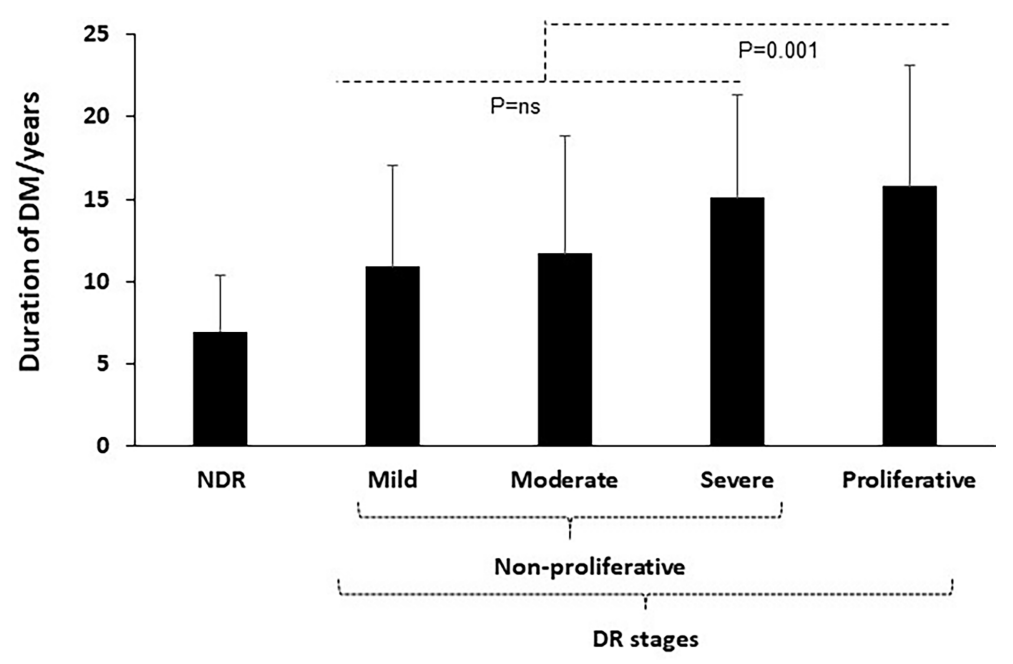

FIGURE 1 | The correlation between duration of T2D/years and severties of DR.

TABLE 2 | Univariate logistic regression analysis model.

\begin{tabular}{|c|c|c|c|c|c|c|c|}
\hline & \multirow[t]{2}{*}{ B } & \multirow[t]{2}{*}{ SE } & \multirow[t]{2}{*}{ Wald } & \multirow{2}{*}{$\begin{array}{c}p \\
\text { value }\end{array}$} & \multirow[t]{2}{*}{ Odds } & \multicolumn{2}{|c|}{$95 \% \mathrm{Cl}$ for OR } \\
\hline & & & & & & Lower & Upper \\
\hline $\mathrm{BMI}\left(\mathrm{kg} \backslash \mathrm{m}^{2}\right)$ & 0.008 & 0.023 & 0.109 & 0.741 & 1.008 & 0.963 & 1.055 \\
\hline $\begin{array}{l}\text { Duration of T2D } \\
\text { (years) }\end{array}$ & 0.122 & 0.019 & 40.554 & $<0.001$ & 1.130 & 1.088 & 1.173 \\
\hline Age (years) & 0.035 & 0.013 & 7.166 & 0.007 & 1.036 & 1.009 & 1.062 \\
\hline Currently smoking & -0.123 & 0.254 & 0.232 & 0.630 & 0.885 & 0.537 & 1.357 \\
\hline $\mathrm{HTN}^{a}$ & 0.651 & 0.284 & 5.265 & 0.022 & 1.917 & 1.100 & 3.342 \\
\hline $\begin{array}{l}\text { Uncontrolled T2D } \\
(\mathrm{HbA} 1 \mathrm{C}>7 \%)\end{array}$ & 1.035 & 0.461 & 5.035 & 0.025 & 2.816 & 1.140 & 6.957 \\
\hline $\begin{array}{l}\text { Normal cholesterol } \\
\text { (normal is below } \\
5.18 \mathrm{mmol} / \mathrm{L} \text { ) }\end{array}$ & -0.791 & 0.271 & 8.523 & 0.004 & 0.453 & 0.266 & 0.771 \\
\hline
\end{tabular}

${ }^{\text {aAverage systolic blood pressure (SBP) of } \geq 140 \mathrm{mmHg} \text { and/or an average diastolic blood }}$ pressure $(D B P)$ of $\geq 90 \mathrm{mmHg}$.

In our sample, we introduced a new data of a cross-sectional study indicating 30\% prevalence of DR in northern West Bank, Palestine. DR stage's severities showed approximately an equal distribution between males and females (1.2:1 male-to-female ratio). Although sample size could be a limited factor for the sampling population, following the reduced impact of confounding variables, duration of T2D could be considered as the most significant risk factor for DR and may be linearly correlated with DR severities.

\section{DATA AVAILABILITY STATEMENT}

The original contributions presented in the study are included in the article/supplementary material. Further inquiries can be directed to the corresponding author.
TABLE 3 | Multivariate logistic regression analysis model.

\begin{tabular}{|c|c|c|c|c|c|c|c|}
\hline & \multirow[t]{2}{*}{ B } & \multirow[t]{2}{*}{ SE } & \multirow[t]{2}{*}{ Wald } & \multirow{2}{*}{$\begin{array}{c}p \\
\text { value }\end{array}$} & \multirow[t]{2}{*}{ Odds } & \multicolumn{2}{|c|}{$95 \% \mathrm{Cl}$ for OR } \\
\hline & & & & & & Lower & Upper \\
\hline Age (years) & 0.004 & 0.016 & 0.051 & 0.822 & 1.004 & 0.973 & 1.035 \\
\hline $\begin{array}{l}\text { Duration of T2D } \\
\text { (years) }\end{array}$ & 0.112 & 0.021 & 27.303 & 0.000 & 1.118 & 1.072 & 1.166 \\
\hline $\mathrm{BMI}\left(\mathrm{kg} \backslash \mathrm{m}^{2}\right)$ & 0.010 & 0.028 & 0.133 & 0.716 & 1.010 & 0.956 & 1.068 \\
\hline Currently smoking & 0.064 & 0.304 & 0.044 & 0.834 & 1.066 & 0.587 & 1.934 \\
\hline $\begin{array}{l}\text { Uncontrolled T2D } \\
(\mathrm{HbA} 1 \mathrm{C}>7 \%)\end{array}$ & 0.808 & 0.544 & 2.205 & 0.138 & 2.244 & 0.772 & 6.524 \\
\hline $\begin{array}{l}\text { Cholesterol (normal is } \\
\text { below } 5.18 \mathrm{mmol} / \mathrm{l})\end{array}$ & -0.385 & 0.305 & 1.595 & 0.207 & 0.680 & 0.374 & 1.237 \\
\hline HTN & 0.574 & 0.325 & 3.121 & 0.077 & 1.775 & 0.939 & 3.356 \\
\hline Constant & -4.549 & 1.920 & 5.616 & 0.018 & 0.011 & & \\
\hline
\end{tabular}

\section{ETHICS STATEMENT}

The ethics committee of An-Najah National University approved the study. The patients/participants provided their written informed consent to participate in this study. Written informed consent was obtained from the individual(s) for the publication of any potentially identifiable images or data included in this article.

\section{AUTHOR CONTRIBUTIONS}

JA formulated the research question, analyzed the data, and had primary responsibility for the final content. RS and MA carried out the research and wrote the draft. AS checked out the statistical analysis. AA revised the clinical data. All authors contributed to the article and approved the submitted version. 


\section{REFERENCES}

1. Lechner J, O'Leary OE, Stitt AW. The Pathology Associated With Diabetic Retinopathy. Vision Res (2017) 139:7-14. doi: 10.1016/j.visres.2017.04.003

2. Jampol LM, Glassman AR, Sun J. Evaluation and Care of Patients With Diabetic Retinopathy. N Engl J Med (2020) 382(17):1629-37. doi: 10.1056/ NEJMra1909637

3. Jones S, Edwards RT. Diabetic Retinopathy Screening: A Systematic Review of the Economic Evidence. Diabetic Med: J Br Diabetic Assoc (2010) 27(3):24956. doi: 10.1111/j.1464-5491.2009.02870.x

4. Nguyen TT, Wang JJ, Sharrett AR, Islam FM, Klein R, Klein BE, et al. Relationship of Retinal Vascular Caliber With Diabetes and Retinopathy: The Multi-Ethnic Study of Atherosclerosis (MESA). Diabetes Care (2008) 31 (3):544-9. doi: 10.2337/dc07-1528

5. Abdeen Z, Jildeh C, Dkeideek S, Qasrawi R, Ghannam I, Al Sabbah H. Overweight and Obesity Among Palestinian Adults: Analyses of the Anthropometric Data From the First National Health and Nutrition Survey (1999-2000). J Obes (2012) 2012:213547. doi: 10.1155/2012/213547

6. Yin L, Zhang D, Ren Q, Su X, Sun Z. Prevalence and Risk Factors of Diabetic Retinopathy in Diabetic Patients: A Community Based Cross-Sectional Study. Medicine (2020) 99(9):e19236. doi: 10.1097/MD.0000000000019236

7. Chobanian AV, Bakris GL, Black HR, Cushman WC, Green LA, Izzo JL, et al. The Seventh Report of the Joint National Committee on Prevention, Detection, Evaluation, and Treatment of High Blood Pressure: The JNC 7 Report. JAMA (2003) 289(19):2560-72. doi: 10.1001/jama.289.19.2560

8. World Health Organization. Definition and Diagnosis of Diabetes Mellitus and Intermediate Hyperglycemia REPORT of a WHO/IDF Consultation. Geneva: WHO (2006).

9. Santos DC, de Melo L, Pizarro MH, Barros B, Negrato CA, Porto LC, et al. Genomic Ancestry as a Risk Factor for Diabetic Retinopathy in Patients With Type 1 Diabetes From an Admixed Population: A Nested Case-Control Study in Brazil. Acta Diabetol (2020) 57(8):937-45. doi: 10.1007/s00592-020-01498-5

10. Kohner EM, Aldington SJ, Stratton IM, Manley SE, Holman RR, Matthews DR, et al. United Kingdom Prospective Diabetes Study, 30: Diabetic Retinopathy at Diagnosis of non-Insulin-Dependent Diabetes Mellitus and Associated Risk Factors. Arch. Ophthalmol. (Chicago Ill: 1960) (1998) 116 (3):297-303. doi: 10.1001/archopht.116.3.297

11. Mohamed Q, Gillies MC, Wong TY. Management of Diabetic Retinopathy: A Systematic Review. JAMA (2007) 298(8):902-16. doi: 10.1001/jama.298.8.902

12. Yang JY, Kim NK, Lee YJ, Noh JH, Kim DJ, Ko KS, et al. Prevalence and Factors Associated With Diabetic Retinopathy in a Korean Adult Population: The 2008-2009 Korea National Health and Nutrition Examination Survey. Diabetes Res Clin Pract (2013) 102(3):218-24. doi: 10.1016/j.diabres. 2013.10.016

13. Lima VC, Cavalieri GC, Lima MC, Nazario NO, Lima GC. Risk Factors for Diabetic Retinopathy: A Case-Control Study. Int J Retina Vitreous (2016) 2:21. doi: 10.1186/s40942-016-0047-6

14. Zhang X, Saaddine JB, Chou CF, Cotch MF, Cheng YJ, Geiss LS, et al. Prevalence of Diabetic Retinopathy in the United States, 2005-2008. JAMA (2010) 304(6):649-56. doi: 10.1001/jama.2010.1111

15. Bamashmus MA, Gunaid AA, Khandekar RB. Diabetic Retinopathy, Visual Impairment and Ocular Status Among Patients With Diabetes Mellitus in
Yemen: A Hospital-Based Study. Indian J Ophthalmol (2009) 57(4):293-8. doi: $10.4103 / 0301-4738.53055$

16. Jost BS, Hilgemberg E, Rodrigues EB, Daniotti AF, Bonamigo EL. Prevalence of Diabetic Retinopathy in Patients Affected by Type 2 Diabetes Mellitus in the City of Luzerna-SC. Arquivos Brasileiros Oftalmol (2010) 73(3):259-65. doi: 10.1590/S0004-27492010000300010

17. Zhou Y, Zhang Y, Shi K, Wang C. Body Mass Index and Risk of Diabetic Retinopathy: A Meta-Analysis and Systematic Review. Medicine (2017) 96 (22):e6754. doi: 10.1097/MD.0000000000006754

18. Cheung N, Wong TY. Obesity and Eye Diseases. Survey Ophthalmol (2007) 52 (2):180-95. doi: 10.1016/j.survophthal.2006.12.003

19. Dirani M, Xie J, Fenwick E, Benarous R, Rees G, Wong TY, et al. Are Obesity and Anthropometry Risk Factors for Diabetic Retinopathy? The Diabetes Management Project. Invest Ophthalmol Visual Sci (2011) 52(7):4416-21. doi: 10.1167/iovs.11-7208

20. Moss SE, Klein R, Klein BE. Cigarette Smoking and Ten-Year Progression of Diabetic Retinopathy. Ophthalmology (1996) 103(9):1438-42. doi: 10.1016/ S0161-6420(96)30486-7

21. Klein R, Klein BE, Davis MD. Is Cigarette Smoking Associated With Diabetic Retinopathy? Am J Epidemiol (1983) 118(2):228-38. doi: 10.1093/ oxfordjournals.aje.a113630

22. Ahmed KR, Karim MN, Bukht MS, Bhowmik B, Acharyya A, Ali L, et al. Risk Factors of Diabetic Retinopathy in Bangladeshi Type 2 Diabetic Patients. Diabetes Metab Syndrome (2011) 5(4):196-200. doi: 10.1016/j.dsx.2012.02.020

23. Davis MD, Fisher MR, Gangnon RE, Barton F, Aiello LM, Chew EY, et al. Risk Factors for High-Risk Proliferative Diabetic Retinopathy and Severe Visual Loss: Early Treatment Diabetic Retinopathy Study Report 18. Invest Ophthalmol Visual Sci (1998) 39(2):233-52.

24. Liu Y, Duan C, Fang D, Liu Y, Xu H, Zheng Y, et al. Protective Factors for Diabetic Retinopathy in Type 2 Diabetes Mellitus Patients: Long Duration of No Less Than 10 Years. J Diabetes Complicat (2019) 33(10):107383. doi: 10.1016/j.jdiacomp.2019.05.014

25. AbuMustafa AM. Clinical and Biochemical Associations With Diabetic Retinopathy in Male Patients in the Gaza Strip. Front Endocrinol (2017) 8:302. doi: $10.3389 /$ fendo. 2017.00302

Conflict of Interest: The authors declare that the research was conducted in the absence of any commercial or financial relationships that could be construed as a potential conflict of interest.

Publisher's Note: All claims expressed in this article are solely those of the authors and do not necessarily represent those of their affiliated organizations, or those of the publisher, the editors and the reviewers. Any product that may be evaluated in this article, or claim that may be made by its manufacturer, is not guaranteed or endorsed by the publisher.

Copyright $\odot 2021$ Amer, Suboh, Abualrob, Shaheen and Abu Shanab. This is an open-access article distributed under the terms of the Creative Commons Attribution License (CC BY). The use, distribution or reproduction in other forums is permitted, provided the original author(s) and the copyright owner(s) are credited and that the original publication in this journal is cited, in accordance with accepted academic practice. No use, distribution or reproduction is permitted which does not comply with these terms. 